\title{
O ACERVO ANTIGO DA BIBLIOTECA DO PORTO DO RIO GRANDE
}

THE ARCHIVE OF THE LIBRARY OF THE PORT OF RIO GRANDE
Enviado em 1 de outubro de 2014
Aceito em 4 de junho de 2015
Gladis Rejane Moran Ferreira ${ }^{1}$
Carla Rodrigues Gastaud ${ }^{2}$

Resumo: Este ensaio tem por objetivo apresentar parte do acervo documental da biblioteca do Porto do Rio Grande, composto por correspondências administrativas manuscritas trocadas entre a segunda metade do século XIX e a segunda década do século $X X$.

Palavras-chave: Manuscritos. Biblioteca. Porto do Rio Grande.

\begin{abstract}
This study aims to present part of the documentary archive belonging to the library of the Port of Rio Grande, comprised of handwritten administrative correspondence produced between the second half of the 19th century and the second decade of the $20^{\text {th }}$.
\end{abstract}

Keywords: Handwritten texts. Library. Rio Grande port.

O objetivo deste ensaio é o de apresentar as correspondências manuscritas que compõem parte do acervo documental da biblioteca do Porto do Rio Grande, procurando mostrar sua importância para a memória da instituição, pois é através da memória que as instituições se reproduzem no seio da sociedade (COSTA, 1997, p. 145). Neste sentido busca-se também registrar seu estado atual de conservação, uma vez que, passados aproximadamente 150 anos de sua produção e circulação, pouco se fez que visasse sua preservação.

Esta documentação, composta por 58 maços, de aproximadamente 200 folhas cada, representa se não toda, pelo menos grande parte das correspondências trocadas pelo Império - que, em 1869 autorizou através do Decreto n. 1.746, a construção de

\footnotetext{
1 Bacharel em Biblioteconomia pela Universidade Federal do Rio Grande. Especialista em Rio Grande do Sul: Política, sociedade e cultura pela Universidade Federal do Rio Grande. Mestranda em Memória Social e Patrimônio Cultural pela Universidade Federal de Pelotas. Bibliotecária da Superintendência do Porto do Rio Grande. E-mail: gladis@portoriogrande.com.br

2 Bacharel em História pela Universidade Federal de Pelotas. Bacharel em Direito pela Universidade Federal de Pelotas. Mestre em História pela Universidade Federal do Rio Grande do Sul. Doutora pela Universidade Federal do Rio Grande do Sul. Professora do Programa de Pós-Graduação em Memória Social e Patrimônio Cultural da Universidade Federal de Pelotas.
} 
docas e armazéns para a movimentação e conservação de produtos importados e exportados.

A informação contida na maioria dos documentos diz respeito às recorrentes tratativas para melhoria do canal de acesso a Barra e Porto. Dentre estas providências, criou-se, em 1846 a Inspetoria da Praticagem da Barra ${ }^{3}$, para dar segurança à transposição das águas no canal da chamada Barra Diabólica ${ }^{4}$ pois, desde tempo remoto, a Barra do Rio Grande apresentou risco às embarcações que zarpavam ou ancoravam no pequeno ancoradouro da província.

O período que compreende a documentação inicia na década de setenta do século XIX, e se estende até a segunda década do século XX. Para fins de organização, os documentos foram assim separados:

- documentos datados de 1869 a 1889, referentes ao período do Governo Imperial;

- documentos datados de 1889 a 1908, referentes ao período do Governo Federal;

- documentos datados de 1908 a 1919, referentes ao período em que o Governo Federal contratou a Compagnie Française du Port e Barra do Rio Grande.

Em 1915 se deu a inauguração dos dois Molhes, o de Leste e o de Oeste e a abertura do Porto Novo da cidade. Tal empreendimento de engenharia foi considerado, na época, a maior obra de engenharia hidráulica da América Latina, movimentando cerca de 14 mil operários que formaram os bairros e vilas até hoje existentes na cidade do Rio Grande (PRADEL, 1979). A partir da inauguração, que se realizou no ano de 1915, o Porto passa a contar sua existência se constituindo entre as maiores instituições do Estado. Porém, aproximadamente 50 anos de tratativas e tentativas de planejamento e execução de obras antecederam esta data e possibilitaram tal empreendimento de engenharia.

Fazem parte deste acervo, documentos oficiais, dentre eles, os Relatórios das primeiras atividades desenvolvidas para dar suporte às obras de engenharia; relatos de plantações de mudas de cedro e pinheiro a fim de fixar as dunas do litoral; as primeiras estacadas de madeira que serviram de partida para a construção da raiz de ambos os Molhes, o de Leste e o de Oeste; Relatórios de Estudo das Condições para Execução dos Projetos de Engenharia, que envolveram grandes períodos de observações

\footnotetext{
3 Instalada na Povoação da Barra, sob a direção de um oficial da armada nacional, servida por práticos conhecedores das tradições antigas dos canais de acesso e por grande número de marinheiros (PRADEL, 1979).

4 Por sua configuração geográfica, a Barra apresentava perigo permanente, e, neste período, ganhou fama de "Barra diabólica" ou "cemitério de navios", tendo em vista sua reduzida acessibilidade (ALVES, 2007)
} 
meteorológicas e dos movimentos das marés. Outros documentos de igual valor são as Atas de Inauguração do Porto Novo e da Barra, datadas de 1915; os primeiros Contratos Firmados Para Aquisição de Bens necessários aos assentamentos dos operários e construção de oficinas, almoxarifados, diretorias, e tudo o que era importante de ser construído para dar condições a grande obra de engenharia, tão necessária.

Também fazem parte do referido acervo os inventários deixados pela Companhia Francesa ${ }^{5}$, que tratam dos bens adquiridos, assim como escrituras de áreas na cidade, na localidade conhecida como Ilha e Lagoa do Ladino. Tais áreas foram desapropriadas a fim de serem aterradas, criando um espaço artificial para a construção do Porto Novo.

O porto aproxima-se de seu centenário de operação, figurando entre os três maiores portos do país ${ }^{6}$. Porém, um olhar um pouco mais atento deve ser lançado sobre estes documentos a fim de conservá-los, pois, as informações contidas nestes suportes darão acesso a história dos grandes projetos de engenharia civil e naval do século XIX; dos primeiros registros de observações ambientais e meteorológicas da costa da região sul do país; do estudo das marés na costa sul brasileira e dos fortes movimento das dunas de areia, que se movimentavam constantemente no litoral, assim como dos fortes movimentos de imigrações de operários, técnicos e de engenheiros ocorridas neste período. Estes e outros assuntos importantes são tratados nestes manuscritos que fazem parte do patrimônio e da memória de um porto brasileiro.

\footnotetext{
${ }^{5}$ Como ficou conhecida a Compagnie Française du Port do Rio Grande do Sul.
}

${ }^{6}$ Boletim Informativo Portuário. 1ํ Trimestre de 2013. Agência Nacional de Transporte Aquaviário/ANTAQ 


\section{LUGARES E ROTINAS DE TRABALHO DESCRITAS NA}

\section{DOCUMENTAÇÃO}

Figura 1: Pequeno ancoradouro da cidade. Meados do século.

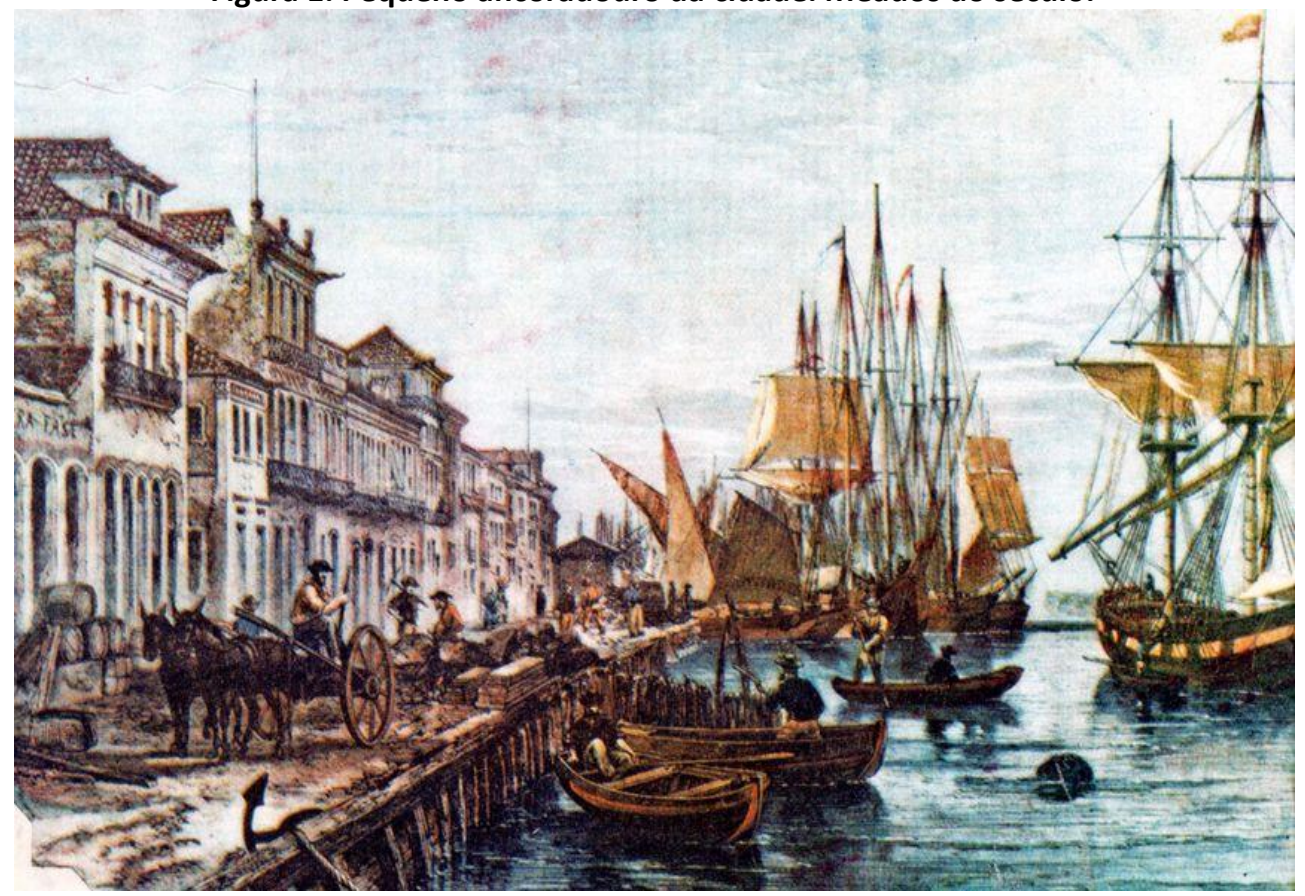

Fonte: Acervo da Biblioteca Riograndense, 2014.

Figura 2 - Porto do Rio Grande em operação Século XIX.

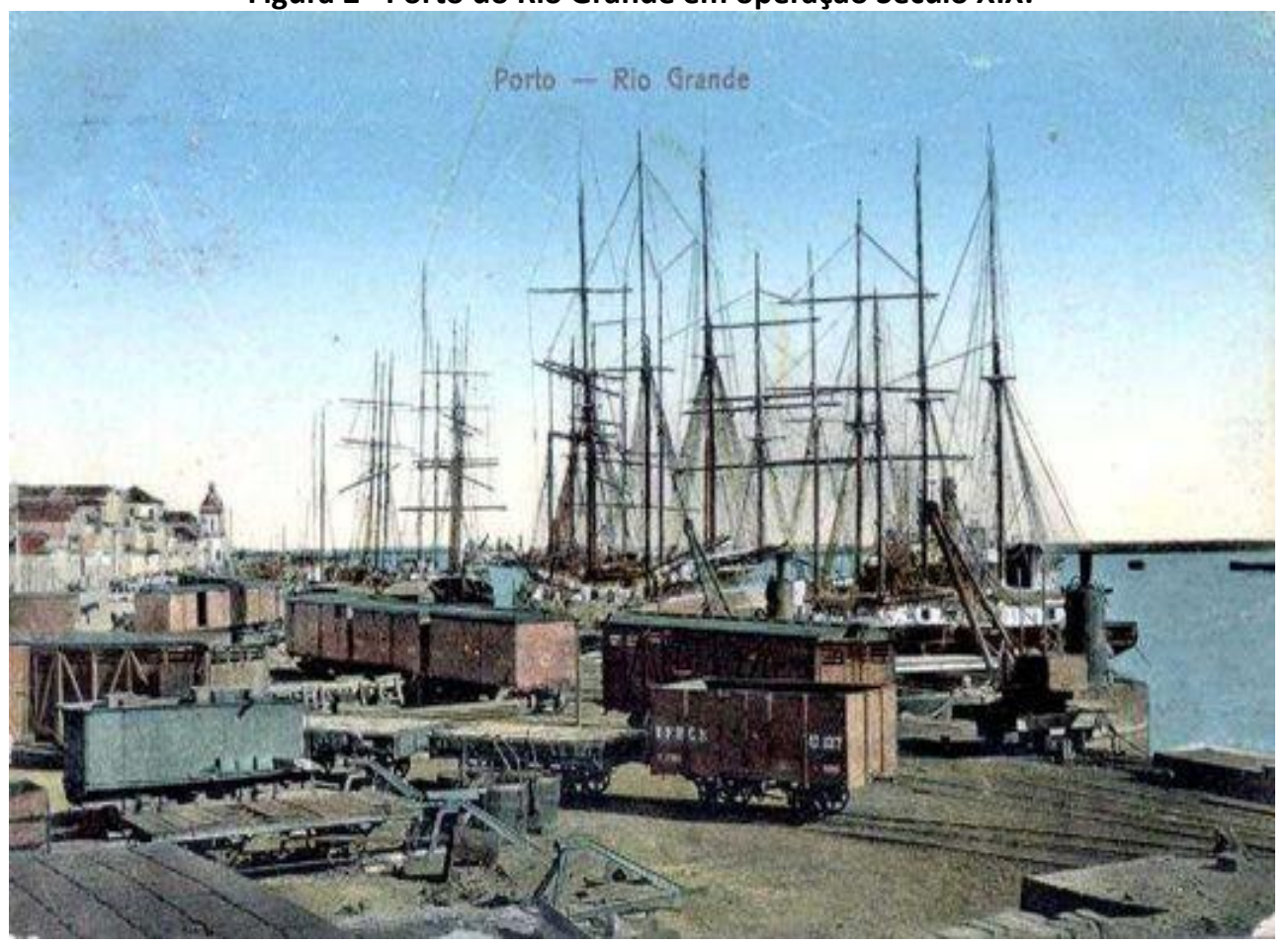

Fonte: Acervo da Biblioteca Riograndense, 2014. 


\section{anuts}

Figura 3 - Construção do Porto Novo. Início do Século XX.

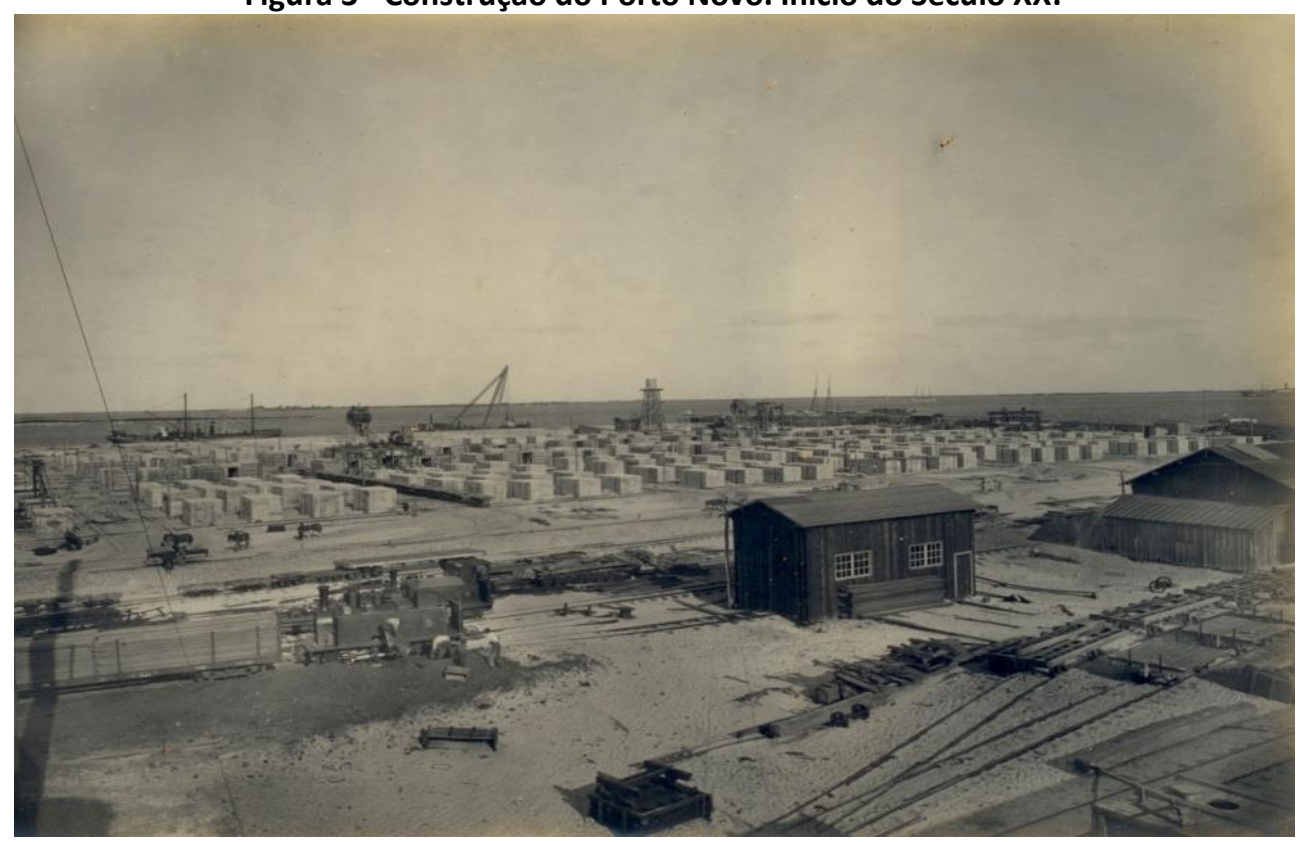

Fonte: Acervo Biblioteca do Porto, 2014.

Figura 4 - Duplicação da linha férrea no Estado para transporte de pedras para a construção de ambos os Molhes da Barra. Início do Século XX.

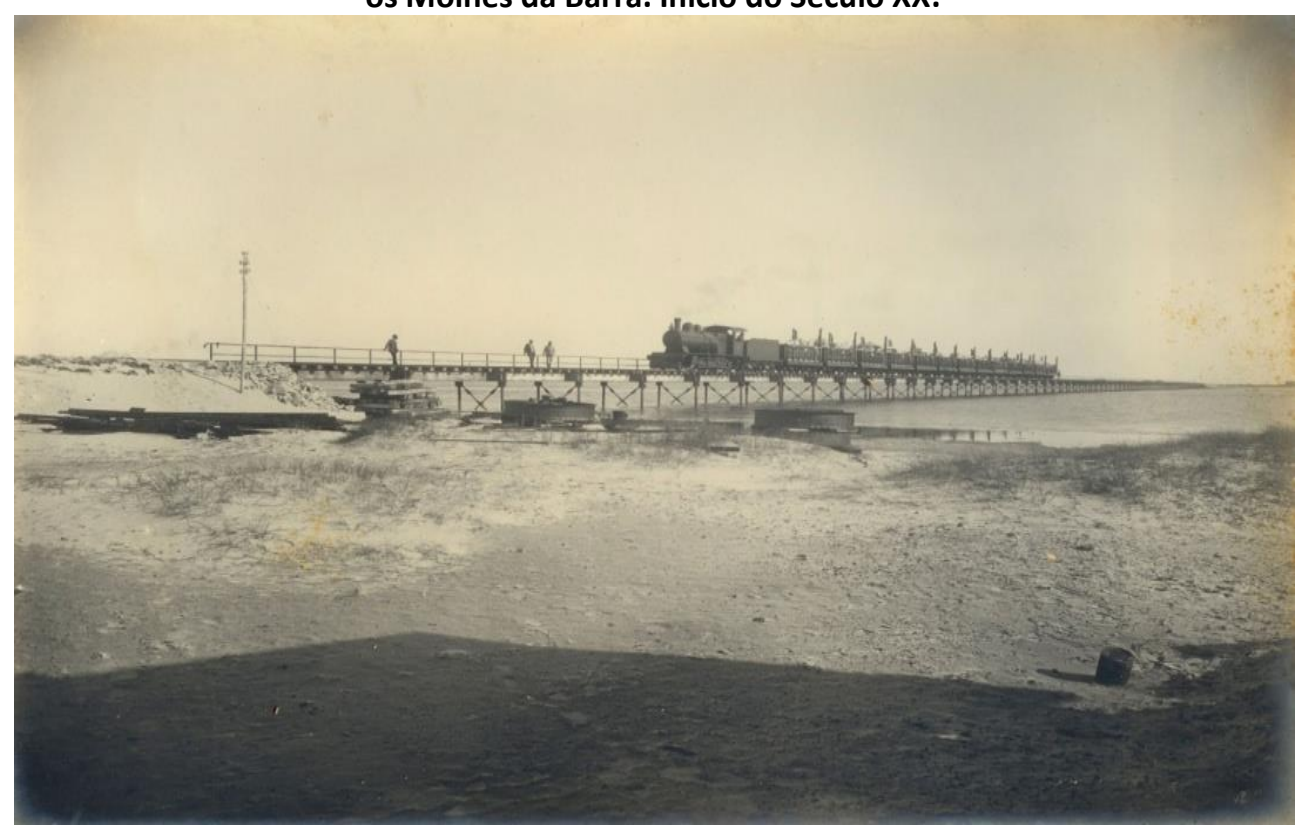

Fonte: Acervo da Biblioteca do Porto, 2014. 
Figura 5 - Retirada das pedras para construção dos molhes. Pedreira do Capão do Leão. Início do Século XX.

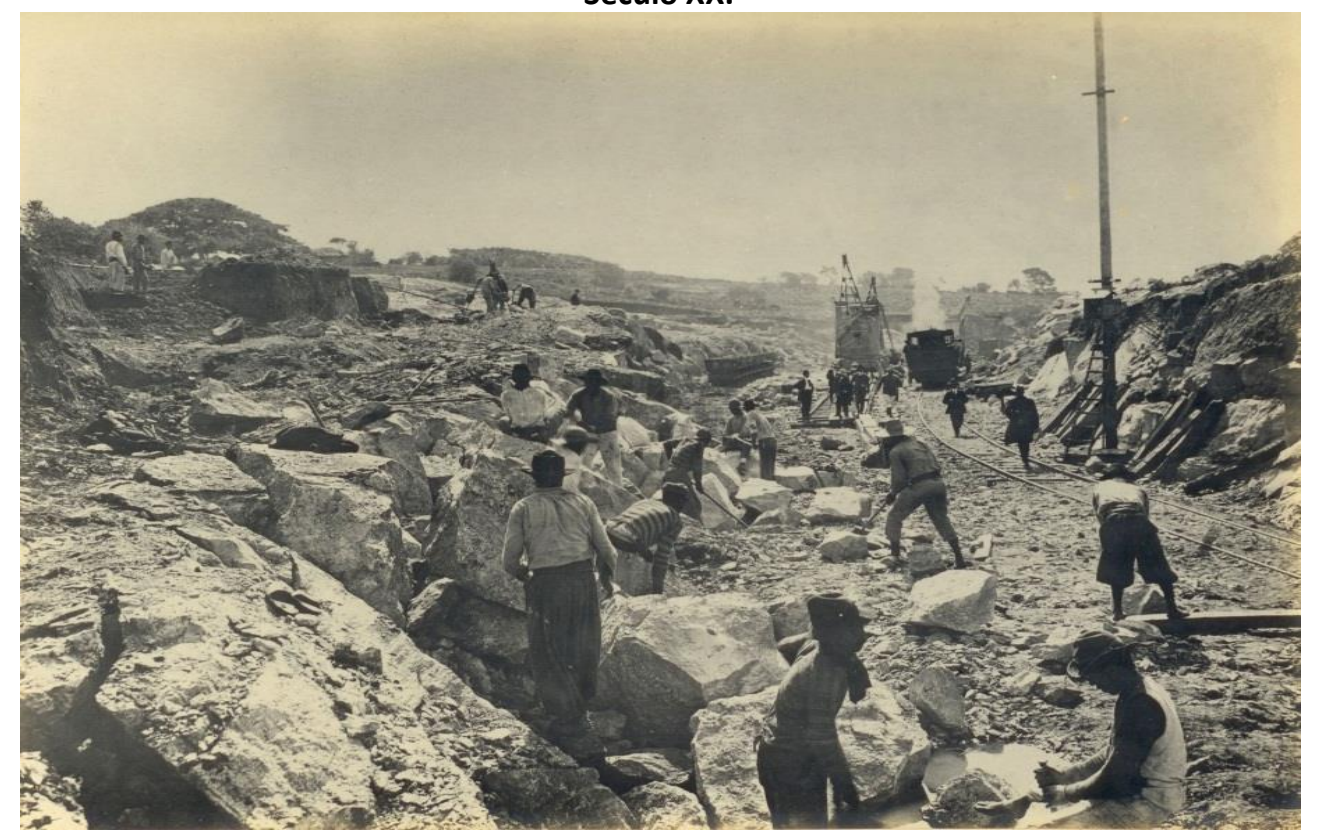

Fonte: Acervo da Biblioteca do Porto, 2014.

Figura 6 - Construção dos Molhes da Barra, pela Compagnie Francaise du Port do Rio Grande do Sul. Início do Século XX.

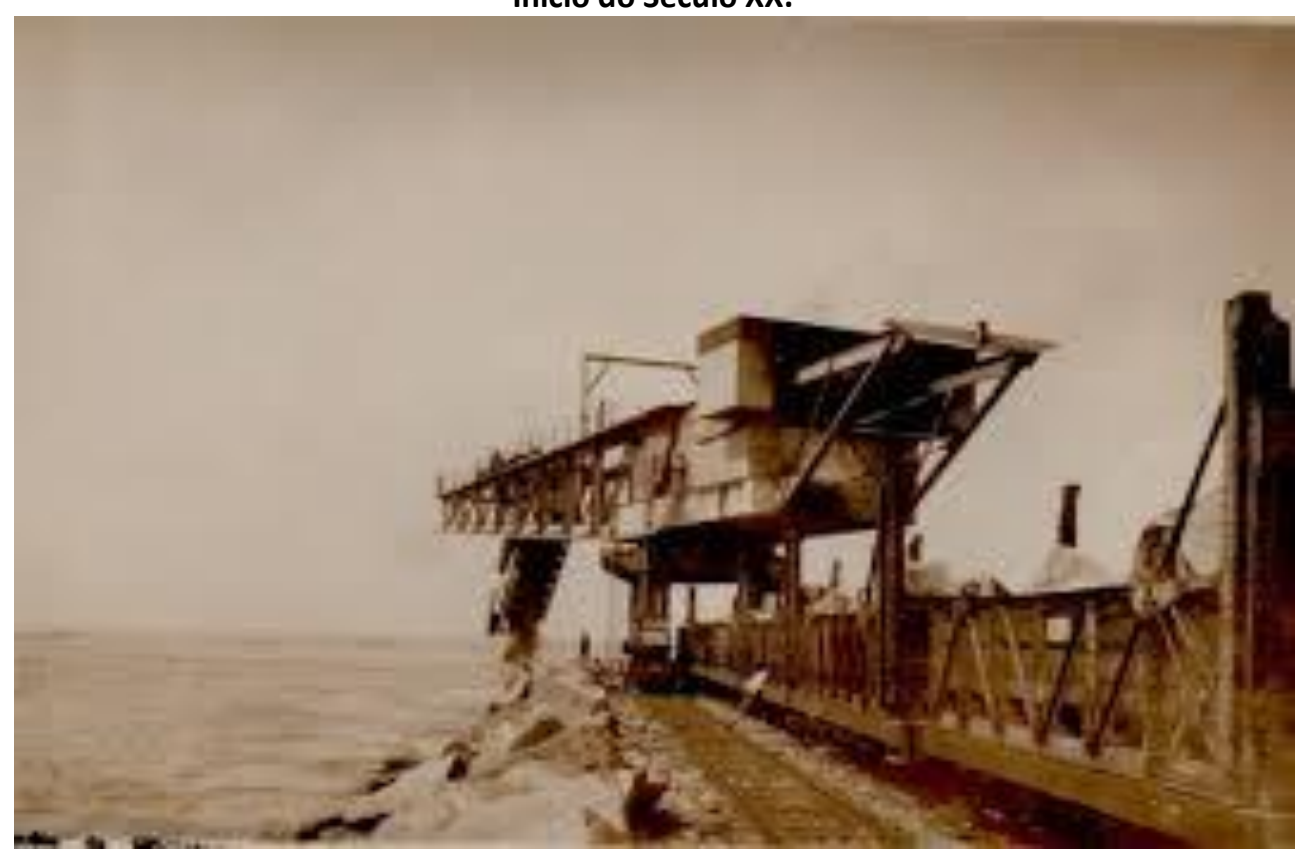

Fonte: Acervo da Biblioteca do Porto, 2014. 
DOCUMENTOS MANUSCRITOS PERTENCENTES AO ACERVO DA SUPERINTENDÊNCIA DO PORTO DO RIO GRANDE, RELATADOS NESTE TRABALHO.

Figura 7 - Documentos Manuscritos dos séculos XIX e XX, dispostos em prateleiras de aço.

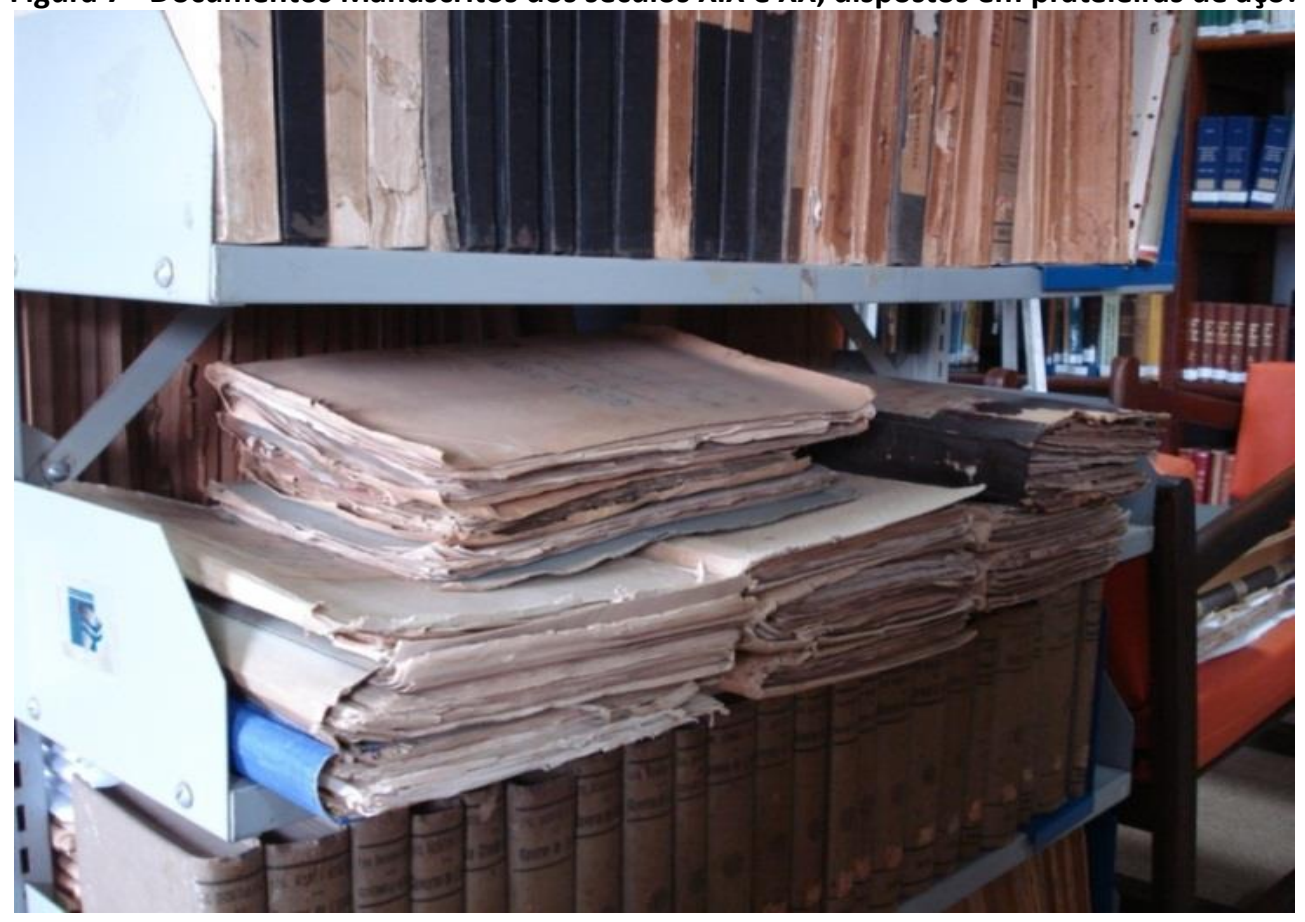

Fonte: Acervo da autora, 2013.

Figura 8 - Documentos datados do final do século XIX e início do século XX.

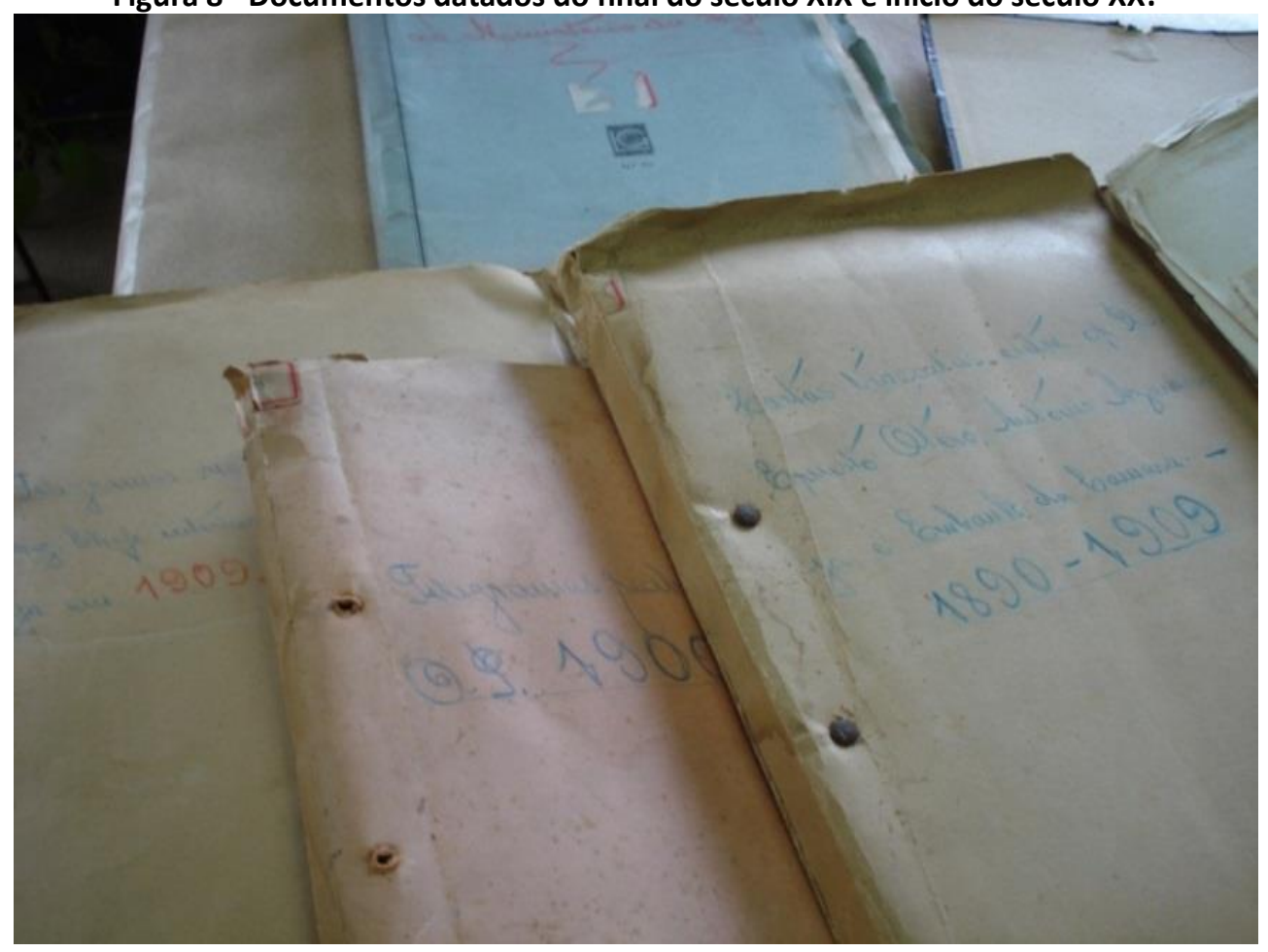

Fonte: Acervo da autora, 2013. 
Figura 9 - Maços envoltos em papel com grampo trilho de metal corrosivo.

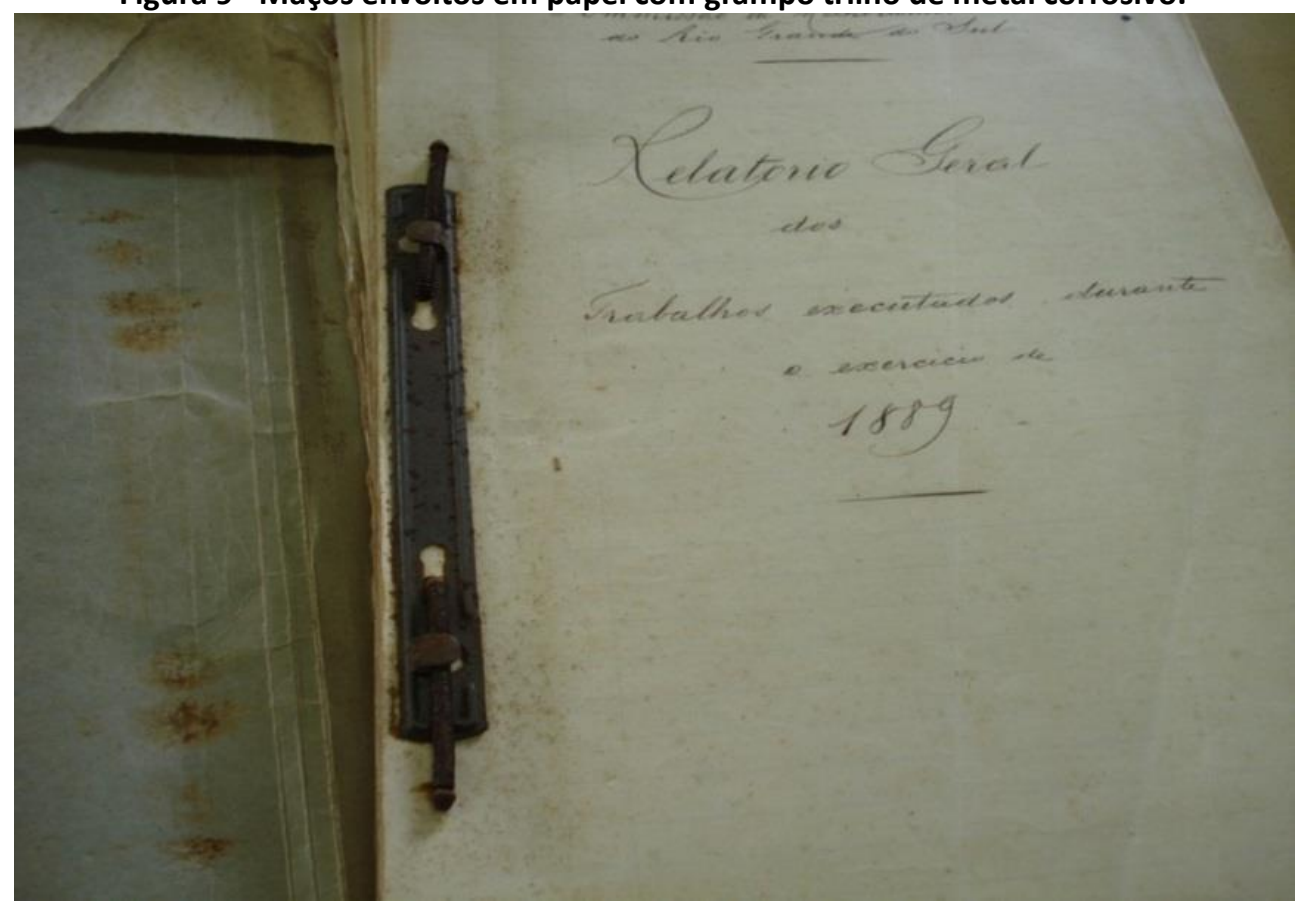

Fonte: Acervo da autora, 2013.

Figura 10: Documentos em maços presos por grampo trilho de material corrosivo.

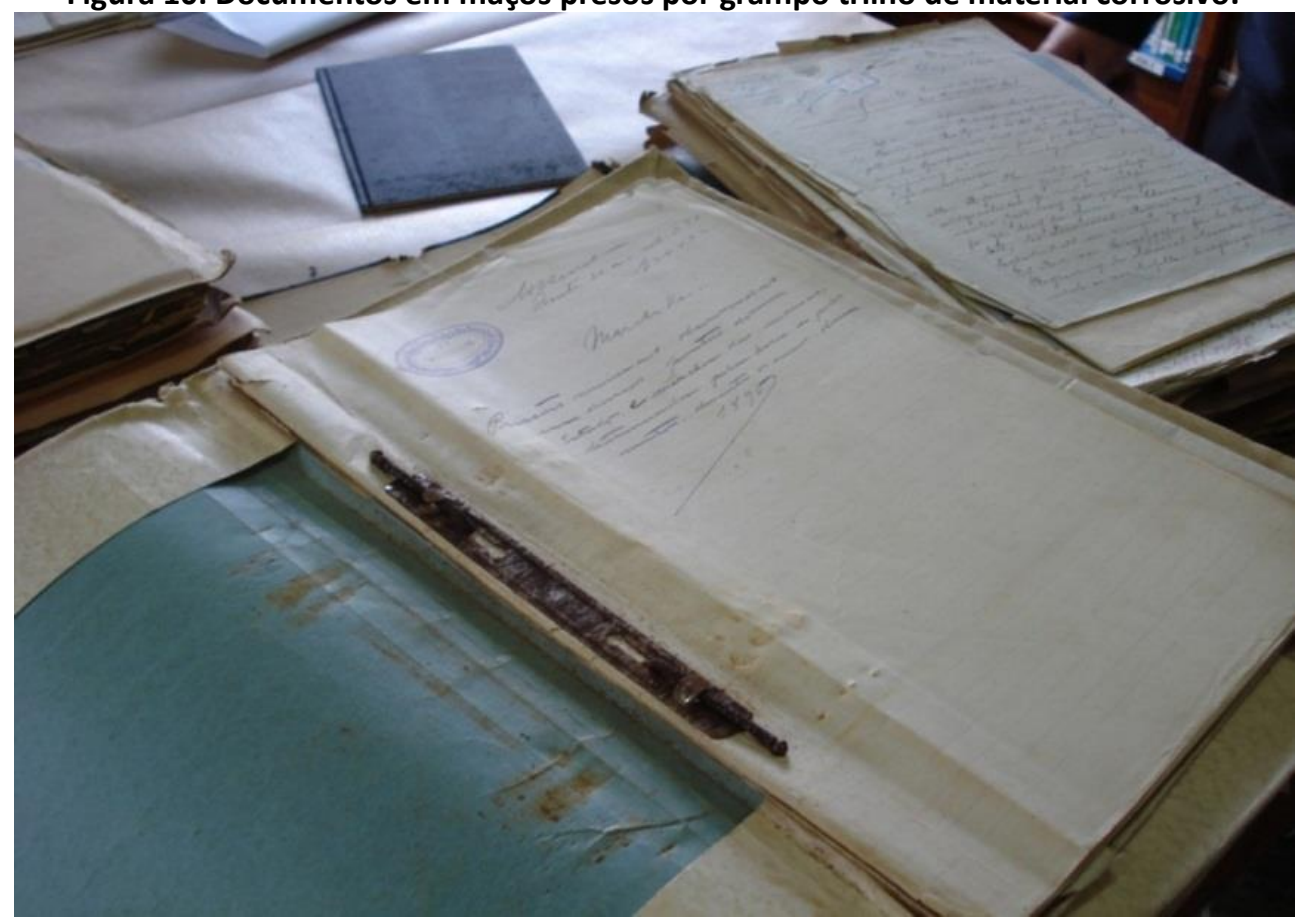

Fonte: acervo da autora. 2013

\section{REFERÊNCIAS}

ALVES, Francisco das Neves. Porto e Barra do Rio Grande: história, memória e cultura portuária. Porto Alegre: Corag, 2008. 2 v. 
BESSA, Altamiro Sérgio Mol. Preservação do patrimônio cultural: nossas casas e cidades, uma herança para o futuro. Belo Horizonte: CREA-MG, 2004.

COSTA, Icléia Thiesen Magalhães. Memória institucional: a construção conceitual numa abordagem teórico-metodológica. Rio de Janeiro, 1997. Tese apresentada ao Curso Doutorado em Ciências da Informação (CNPq/IBICT,UFRJ/ECO).

PRADEL, Antonio. Histórico da Barra do Rio Grande: comemorando os 135 anos de fundação da Câmara do Comércio. 1979. 